\title{
21st Birthday
}

In the year 1968 we celebrate the 21 st birthday of the Journal of Clinical Pathology. The Journal began modestly. About 48 pages were published each quarter in 1949 having been preceded by the Proceedings of the Association of Clinical Pathologists which was published as a single pamphlet for the ACP and at their expense by the Curwen Press in 1945. In each issue, from the beginning until the present day, each main discipline of pathology has been represented: today pathology is of increasing complexity and this is reflected in the variety of papers to be found in any of the present volumes. Technical methods, also, appear in each issue and these have been of the greatest usefulness to working pathologists. From the beginning we insisted on fine illustrations and, even in the difficult post-war years when paper was hard to obtain and sometimes of poor quality, the excellence of the illustrations (occasionally in colour) has been a feature of the Journal. Another feature of the Journal throughout its existence has been the publication of occasional review papers. These won high commendation because they were reviews in the exact sense of that word. The invited authors evaluated the subject which was being discussed and, in so doing, placed in the context of the literature and of present-day practice the topic being reviewed.

Today, the Journal of Clinical Pathology appears six times a year, and the annual volume is a mighty one, not only because six parts are presented to each subscriber but also because in recent years one or more symposia have been published in association with the Journal and these, so far, have been included in the bound volumes. Some of these symposia are the proceedings of conferences organized by the Association of Clinical Pathologists, for example, that on the thyroid gland and, last year, we published the first symposium organized by the College of Pathologists on organ and tissue transplantation. The College of Pathologists held its second symposium on acute respiratory diseases, and this will shortly be published in association with the Journal. For the future, readers can expect supplements on carbohydrate metabolism (Association of Clinical Pathologists) and on laboratory data processing and automation (College of Pathologists). The policy of publishing such symposia, some as supplements in close association with the Journal and others within its covers, has been most successful, and we are looking forward to expanding it so that these discussions are published as guide lines for the present and a record for the future.

We hope that we are interpreting the complexities of modern clinical pathology as our readers wish and that we may also be sensitive enough to be aware of current trends, and to adapt the Journal according to the exigencies of the times. 